Исследования овощей на содержание марганца и меди показали достаточно высокое варьирование их концентраций в разных районах Горного Алтая. Определена линейная положительная зависимость накопления микроэлементов от содержания их в почве.

Наибольшим уровнем накопления изученных элементов характеризуется картофель и свекла. В малых количествах элементы определены в луке, огурцах и томатах (таблица 2).

Таблица 2.

Содержание марганича и меди в некоторых овощчах Горного Алтая, мг/кг

\begin{tabular}{|c|c|c|c|c|c|c|c|}
\hline \multirow{2}{*}{ Элемент } & Картофел & Свекла & Морковь & Лук & Капуста & Огурец & Томаты \\
\hline \multirow{2}{*}{$\mathrm{Mn}$} & $0,3-3,1$ & $0,7-6,7$ & $0,1-1,9$ & $0,6-3,1$ & $0,6-3,3$ & $0,1-2,2$ & $0,1-0,8$ \\
& 1,4 & 3,1 & 0,8 & 1,2 & 1,9 & 0,4 & 0,5 \\
\hline \multirow{2}{*}{$\mathrm{Cu}$} & $0,3-1,4$ & $0,4-1,5$ & $0,06-0,9$ & $0,2-0,5$ & $0,12-0,78$ & $0,03-0,63$ & $0,11-1$ \\
& 0,7 & 0,8 & 0,5 & 0,3 & 0,4 & 0,3 & 0,3 \\
\hline
\end{tabular}
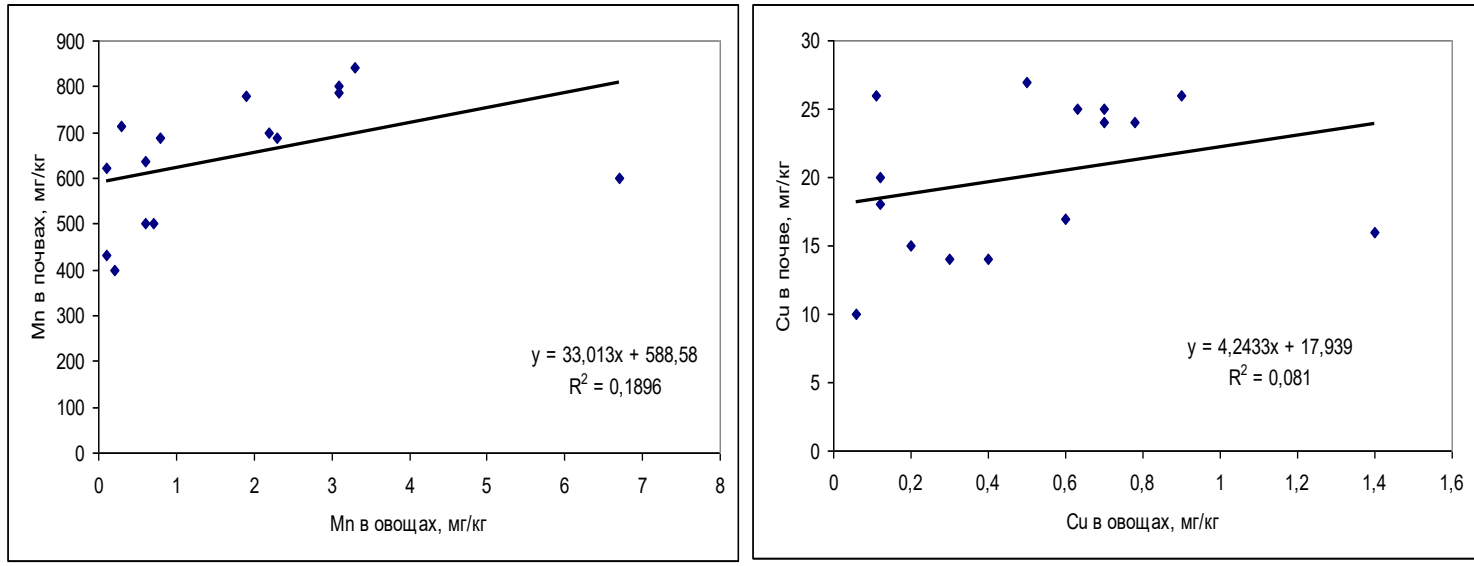

Зависимость содержания марганца и меди в овощах от содержания их в почве

$* * *$

1. Ильин, В.Б. Биогеохимия и агрохимия микроэлементов ( $\mathrm{Mn}, \mathrm{Cu}, \mathrm{Mo}, \mathrm{B})$ в южной части Западной Сибири / В.Б Ильин. - Новосибирск, Наука, 1973. - 392 с.

2. Ильин В.Б., Сысо А.И. Микроэлементы и тяжелые металлы в почвах и растениях Новосибирской области. Новосибирск: Изд-во СО РАН, 2001229 с.

3. Кабата-Пендиас, А. Микроэлементы в почвах и растениях / А. Кабата-Пендиас, Х. Пендиас. Новосибирск, М.: Мир,1989. - 439 с.

4. Ковальский, В.В. Микроэлементы в почвах СССР / В.В. Ковальский, Г.А. Андрианова. - М.: Наука, 1970. - 179 c.

5. Мальгин, М.А. Биогеохимия микроэлементов в Горном Алтае / М.А. Мальгин. - Новосибирск, Наука, 1978. $-272 \mathrm{c}$.

\title{
Хмара К.А.
}

Влияние содержания сахаров в хвое текущего побега у Picea abies [L.] Karst и температурного режима почвы на степень повреждения подроста от заморозков

doi: $10.18411 / \mathrm{j}-09-2018-83$

idsp: 000001:lj-09-2018-83

\section{Аннотация}

Одним из основных факторов, влияющих на процесс развития подроста Picea abies [L.] Karst в районах Европейского севера, является воздействие на рост и развитие особей ели весенне-летних заморозков. Повреждение текущего побега при воздействии 
отрицательных температур приводит к замедлению роста всего растения. Для успешного лесовосстановления еловых лесов необходимо установить причины различной устойчивости елового подроста к заморозкам. При изучении факторов влияющих на способность растений к устойчивости их к заморозкам, болышое внимание уделялось изучению зависимости устойчивости к повреждениям отрицательными температурами от содержания сахаров в растениях. Нами было изучено содержание растворимых сахаров в текущем побеге Picea abies [L.] Karst. Установлена зависимость устойчивости текущего побега подроста ели к заморозкам от содержания в них растворимых сахаров. Анализ полученных данных показал, что особи ели в побегах которых, содержание растворимых сахаров в полтора раз выше, значительно устойчивее к повреждениям от заморозков.

Большую роль в устойчивости подроста ели к повреждениям от заморозков играет фазы роста побегов. Одним из факторов влияющих на фазы роста побегов - является температурный режим почвы в корневой зоне растения. Для изучения влияния температурного режима почвы были подобраны два участка культур Picea abies [L.] Karst, с различной степенью повреждения побегов заморозками. Установлено, что в процессе вегетационного периода температурный режим почв на участках с различным влиянием заморозков на особи ели, значительно отличаются. Так, на участке где особи ели почти не подвержены влиянию заморозков, прогревание почвы происходит значительно медленнее, оттаивание почвы происходит постепенно, а на участке где $100 \%$ особей ели повреждаются заморозками, оттаивание почвы и ее прогревание происходит более интенсивно. В процессе вегетационного периода до его окончания, температура почвы на участке, где 100\% особей ели повреждаются заморозками, на 1-2 гр. выше, температуры почвы на участке не подверженном влиянию заморозков.

Ключевые слова. Заморозки, температура почвы, ель обыкновенная, сахара.

\section{Введение}

В районах Европейского севера (Архангельская область, КОМИ) действие весенне-летних заморозков на растения наблюдается в течение одного-двух месяцев и может происходить во время вегетационного периода неоднократно. Одной из главных задач при искусственном лесовосстановлении является установление причин способствующих повреждению подроста Picea abies [L.] Karst заморозками и разработка способов снижающих отрицательное воздействие заморозков на восстановление еловых лесов.

Основное внимание уделяется отбору генетически устойчивых особей Picea abies [L.] Karst к весенне-летним заморозкам. В основном исследования направлены на изучение устойчивости растений к воздействию отрицательных температур в период покоя. Изучались способы повышения морозоустойчивости различных растительных культур методом предварительной закалки отрицательными температурами, обработкой различными веществами повышающими степень морозоустойчивости $[1,2]$.

Установлено, что повышение уровня углеводов в растении способствует повышению морозоустойчивости. Так, по данным Труновой Т.И. и Зверева Г.Н., раствор хлорного натрия не защищает хлоропласты от вредного действия отрицательных температур, раствор же сахарозы оказывает защитное действие [3]. Все сахара оказывают защитное действие, если они утилизируются растением. Обнаружена связь между содержанием различных групп углеводов в растении в зависимости от фазы роста. Так, у ели при интенсивном росте происходит накопление моносахаридов и крахмала, при прекращении роста побегов баланс углеводов изменяется, увеличивается содержание дисахаридов и олигосахаридов, уменьшается содержание глюкозы и крахмала [4]. По данным Захарчук Н. В. при снижении температуры до небольших отрицательных значений в цветках сорта Флорина происходит интенсивный гидролиз крахмала (его содержание уменьшается более чем на $40 \%$ ), превращающегося в растворимые сахара и, 
кроме того, в липиды (содержание возрастает в 1,5 раза) [5]. Дорошенко Т. Н считает важными диагностическими критериями заморозкоустойчивости характер и степень изменения под влиянием стрессора совокупности физиолого-биохимических показателей цветков: содержание крахмала, глюкозы и липидов [6].

Исследователи, изучавшие повреждения, причиненные поздневесенними заморозками, отмечали зависимость степени повреждения от степени раскрываемости почек (от фазы роста побегов), а так же показали, что сеянцы, характеризующиеся медленным ростом в предыдущий вегетационный год, повреждались заморозками в большей степени [7].

Hanners Mats отметил, что сеянцы наиболее чувствительны к заморозку в момент раскрывания почек и появления кончиков молодой хвои между чешуйками. Через 1-2 недели повреждаемость снижалась в два раза [7]. Изучение изменения углеводного баланса у особей ели в зависимости от степени повреждения их заморозками будет способствовать обнаружению селективных признаков, позволяющих отобрать наиболее устойчивые особи ели.

Данные результаты позволяют сделать предположение о том, что степень повреждаемости побегов Picea abies [L.] Karst поздневесенними и летними заморозками связана с углеводным балансам побегов.

Основная цель исследования - определить зависимость степени устойчивости к заморозкам побегов ели от содержания в них растворимых сахаров, установить влияние температурного режима почвы на повышение устойчивости подроста ели к заморозкам.

\section{Материалы и методы исследования}

Для проведения экспериментальных работ закладывались пробные площади. На каждой пробе не менее ста особей ели. Все деревья были пронумерованы. Для наблюдения за температурным режимом на пробных площадях были установлены минимальные термометры на поверхности почвы и на высоте 1,5 метров и 2 недельных термографа. Во время вегетационного периода велись фенологические наблюдения, по методике Булыгина Н.Е. описывалась морфология всех деревьев на пробных площадях [8]. После разделения всех особей ели по степени повреждения их заморозками проводили анализ изменения содержания сахаров в побегах. Образцы для анализа заготавливались с боковых побегов, с одной экспозиции кроны. Все образцы подвергались сушке. На дно сосуда наливали воду. Растительный материал помещали в марлевый мешок. Так чтобы он не соприкасался с водой. Сосуд закрывали крышкой и воду кипятили 15-20 минут. Затем образцы сушили в сушильном шкафу до воздушносухого состояния при $50-60^{\circ} \mathrm{C}$.

\section{Определение сахаров}

Определение сахаров в испытуемых образцах проводили методом описанным Плешковым Б.Н.[9]. 2 г. свежего материала хорошо измельчали, переносили в стакан или коническую колбу объемом 50-100 мл и заливали 10 мл 96\% спирта. Помещали на водяную баню и трижды доводим до кипения при помешивании (в нашем случае образцы в воздушно-сухом состоянии). Охлаждаем, после осаждения растительного материала фильтруем в фарфоровую чашку объемом 50 мл. сливаем прозрачный спиртовой раствор, в осадок добавляем 10 мл 80\% спирта, перемешиваем, нагреваем на водяной бане до кипения, охлаждаем, фильтруем (все процедуры с осадком проводим два раза). Затем осадок переносим на фильтр и промываем дважды теплым спиртом. Спирт выпариваем при $30-40^{\circ} \mathrm{C}$ на водяной бане. Растворяем в 5-7 мл воды, переносим в мерную колбу объемом 50 мл. доводим до метки, перемешиваем. При подготовке образцов для колориметрирования, 1 мл раствора, содержащего 10-70 мкг сахаров, переносим в широкую пробирку диаметром 16-20 мм и добавляем 1 мл 5\%-ного водного раствора фенола (50 г свежеперегнанного фенола растворяем в 1 мл воды). После этого в пробирку приливаем точно 5 мл химически чистой серной кислоты (плотность 1,84). Кислоту берем пипеткой с грушей и быстро вливаем в жидкость, содержащуюся в пробирке. Пробирки 
оставляем на 10 минут при $25-30^{\circ} \mathrm{C}$ для развития окраски. Интенсивность окраски определяем на спектрофотометре при 490 нм. Концентрацию устанавливаем по калибровочному графику $\left(500\right.$ мг высушенной при $60^{\circ} \mathrm{C}$ сахарозы растворяем в колбе объемом 500мл, доводим до метки, перемешиваем. Берем 7 колб по 100 мл, вносим 1,2.3, 4, 5, 6, 7 мл раствора сахаров, доводим до метки, берем из каждой по 10 мл и окрашиваем фенолом и серной кислотой.

\section{Результаты и их обсуждение}

На участке подверженному постоянному влиянию отрицательных температур во время вегетационного периода были заложены три пробные площади. Пробные площади были заложены в лесных культурах на теретории Луковецкого лесничества. Все деревья на пробных площадях были пронумерованы, измерены высоты и диаметры. (Таблица №1).

На участке 1 средняя высота составила 207.7 см, средний диаметр 2.1 см; на участке $2-\mathrm{H} \mathrm{cp} .-213.6 \mathrm{~cm}$, dcp $-2.4 \mathrm{~cm}$; на участке $3-\mathrm{H} \mathrm{cp} .-149.5 \mathrm{~cm}, \mathrm{~d}$ cp. $-0.7 \mathrm{~cm}$.

В течение наблюдаемого периода, после установления ночных положительных температур было отмечено понижение температуры до отрицательных значений в 11-ти случаях на уровне кроны деревьев.

Таблица 1

Средние высоты и диаметр на пробных площзадях

\begin{tabular}{|c|c|c|c|c|c|c|}
\hline \multirow{2}{*}{$\begin{array}{c}\text { № } \\
\text { Пробной } \\
\text { площади }\end{array}$} & \multicolumn{2}{|c|}{ Средняя высота } & \multicolumn{3}{c|}{ Средний диаметр } \\
\cline { 2 - 7 } & $\mathrm{X} \pm \mathrm{mx}, \mathrm{cm}$ & $\mathrm{C}, \%$ & $\mathrm{P}, \%$ & $\mathrm{X} \pm \mathrm{mx}, \mathrm{cm}$ & $\mathrm{C}, \%$ & $\mathrm{P}, \%$ \\
\hline 1 & $207.7 \pm 7.9$ & 34.4 & 3.8 & $2.1 \pm 0.2$ & 87.5 & 9.7 \\
\hline 2 & $213.6 \pm 5.8$ & 27.0 & 2.7 & $2.4 \pm 0.2$ & 76.1 & 7.6 \\
\hline 3 & $149.5 \pm 7.9$ & 32.6 & 5.3 & $0.7 \pm 0.2$ & 83.2 & 29.1 \\
\hline
\end{tabular}

Интенсивность заморозков была различной используя метод разделения заморозков по интенсивности и продолжительности по Буркину И.А на данных пробных площадях наблюдались слабые заморозки (до $-3^{\circ} \mathrm{C}$ ) девять раз; средние (от $-3^{\circ} \mathrm{C}$ до $-5^{\circ} \mathrm{C}$ ) три раза и сильные (от $-5^{\circ} \mathrm{C}$ и ниже) не наблюдались. По продолжительности заморозки были короткие, до 5 часов и средней продолжительности от 5 до 12 часов. На пробных площадях 1 и 2 наблюдались в основном только короткие заморозки, лишь однажды заморозок был средней продолжительности. На пробной площади 1 в двух случаях отмечались заморозки средней продолжительности.

Влияние заморозков на рост особей ели

Во время вегетационного периода были проведены наблюдения за степенью повреждения растущих особей ели в зависимости от воздействия на них весенне-летних заморозков.

Первые видимые повреждения особей ели были зарегистрированы при понижении температуры до $-5^{\circ} \mathrm{C}$, которое произошло с 22 на 23 июня. При этом от заморозка пострадали в основном боковые побеги длиной от 1 до 2,5 см, в нижней и средней части кроны. Повторное повреждение произошло от заморозка с 3 на 4 июля, когда температура понижалась до $-3^{\circ} \mathrm{C}$. При этом основная масса поврежденных побегов находилась в верхней части кроны. Длина пострадавших побегов составляла от 3 до 12 см.

При учете степени повреждаемости особей ели проводили подсчет побегов поврежденных заморозком. Все деревья были разделены на 4 группы:

1. особи, не поврежденные заморозком

2. особи, у которых в результате заморозка пострадало менее 10 побегов

3. особи, у которых пострадало от 10 до 20 побегов

4. особи, у которых пострадало более 20 побегов

После заморозка с 22 на 23 июня на пробной площади 1 пострадало 45\% всех особей, на пробе 2 - 63\%..Средняя высота наиболее пострадавших особей, как на пробе 1 , 
так и на пробе 2, была почти одинаковой, соответственно 183.7 см и 188.7 см, при этом значительно уступала средней высоте менее пострадавших особей в среднем на 20 - 40 см. (Таблица №2).

При последующих заморозках количество пострадавших особей увеличивалось, но средняя высота деревьев, которые пострадали от заморозков в меньшей степени, была выше, чем у особей имеющих более высокую степень повреждения.

Три процента всех особей ели не пострадали от весенне-летних заморозков. В результате проведенных наблюдений были выделены две группы деревьев: устойчивая и неустойчивая. Устойчивая - повреждения текущего побега у подроста ели не наблюдалось. Неустойчивая - повреждения текущего побега у подроста ели наблюдалось у более 20 текущих побегов.

Таблииа 2

Средняя высота деревьев ели в зависимости от степени повреждения заморозками

\begin{tabular}{|c|c|c|c|c|c|}
\hline \multirow[t]{2}{*}{ № пробы } & \multirow[t]{2}{*}{$\begin{array}{l}\text { Время } \\
\text { учета }\end{array}$} & \multicolumn{4}{|c|}{$\begin{array}{c}\text { Количество поврежденных побегов на одной особи, в шт. } \\
\text { В знаменатели средняя высота, в см. } \\
\text { числитель количество особей в шт. }\end{array}$} \\
\hline & & 0 & До 10 & $10-20$ & Более 20 \\
\hline \multirow{3}{*}{1} & $28 / 6$ & $\begin{array}{c}197.6 \\
55\end{array}$ & $\begin{array}{c}223.8 \\
41\end{array}$ & $\begin{array}{c}189.3 \\
4\end{array}$ & 0 \\
\hline & $8 / 7$ & $\begin{array}{c}172.8 \\
16\end{array}$ & $\begin{array}{c}215.6 \\
61\end{array}$ & $\begin{array}{c}225.4 \\
16\end{array}$ & $\begin{array}{c}205.0 \\
7\end{array}$ \\
\hline & $19 / 8$ & $\begin{array}{c}214.0 \\
3\end{array}$ & $\begin{array}{c}211.0 \\
56\end{array}$ & $\begin{array}{c}201.8 \\
30\end{array}$ & $\begin{array}{c}215.8 \\
11\end{array}$ \\
\hline \multirow{3}{*}{2} & $27 / 6$ & $\begin{array}{c}285.9 \\
37\end{array}$ & $\begin{array}{c}208.4 \\
52\end{array}$ & $\begin{array}{c}188.7 \\
11\end{array}$ & 0 \\
\hline & $6 / 7$ & $\begin{array}{c}225.7 \\
12\end{array}$ & $\begin{array}{c}222.9 \\
52\end{array}$ & $\begin{array}{c}199.4 \\
23\end{array}$ & $\begin{array}{c}204.9 \\
13\end{array}$ \\
\hline & $18 / 8$ & $\begin{array}{c}290.3 \\
3\end{array}$ & $\begin{array}{c}226.6 \\
34\end{array}$ & $\begin{array}{c}209.6 \\
35\end{array}$ & $\begin{array}{c}201.3 \\
28\end{array}$ \\
\hline
\end{tabular}

Содержание растворимых сахаров в почка-побегах

Для определения содержания суммарного количества всех растворимых сахаров в почка-побегах ели, накануне ночного заморозка, произошедшего с 22 на 23 июня (при котором произошло видимое повреждение побегов) были взяты образцы побегов. В данный период времени происходило интенсивное развитие текущего прироста. Второе взятие образцов было осуществлено 13 июля после окончания роста побегов в длину.

Все особи ели, у которых были взяты образцы побегов для анализа, на содержания сахаров, были разделены на две группы: устойчивая и неустойчивая.

Таблиия 3

Содержание растворимых сахаров в побегах ели.

\begin{tabular}{|c|c|c|c|}
\hline \multirow{2}{*}{$\begin{array}{c}\text { Время } \\
\text { взятия } \\
\text { образца }\end{array}$} & \multirow{2}{*}{$\begin{array}{c}\text { № пробной } \\
\text { площади }\end{array}$} & \multicolumn{2}{|c|}{$\begin{array}{c}\text { Содержание растворимых сахаров в хвое побега, } \\
\text { в мг/г на сух. вес. }\end{array}$} \\
\cline { 2 - 4 } 22 июня & 1 & устойчивая & неустойчивая \\
\cline { 2 - 4 } $\begin{array}{c}\text { накануне } \\
\text { заморозка }\end{array}$ & 2 & $90.9 \pm 0.12$ & $65.2 \pm 0.21$ \\
\hline \multirow{3}{*}{13 июля } & 3 & $91.7 \pm 0.23$ & $73.3 \pm 0.19$ \\
\cline { 2 - 4 } & 1 & $99.8 \pm 0.14$ & $61.6 \pm 0.11$ \\
\cline { 2 - 4 } & 2 & $66.4 \pm 0.17$ & $77.4 \pm 0.16$ \\
\hline
\end{tabular}

Анализ полученных данных показал, что особи ели в побегах которых, содержание растворимых сахаров в полтора раз выше, значительно устойчивее к повреждениям от заморозков. 
При изучении влияния температуры почвы на рост подроста ели были заложены две пробные площади: Одна пробная площадь в лесных культурах, где 100\% особей ели повреждаются заморозками, лиственные породы отсутствуют. Среднее высота - 1.8 м. Вторая пробная площадь на участке, где заморозками повреждались отдельные особи, часть лиственных пород была оставлена после рубок ухода. Среднее высота - 3.8 м.

На данных пробных площадях производили измерение температурного режима почв, в вегетационный период, на глубине 15 см и 30 см. Термометром ТК5-0,5. На рис 1, 2 приведена динамика изменения температуры почвы в процессе вегетационного периода.

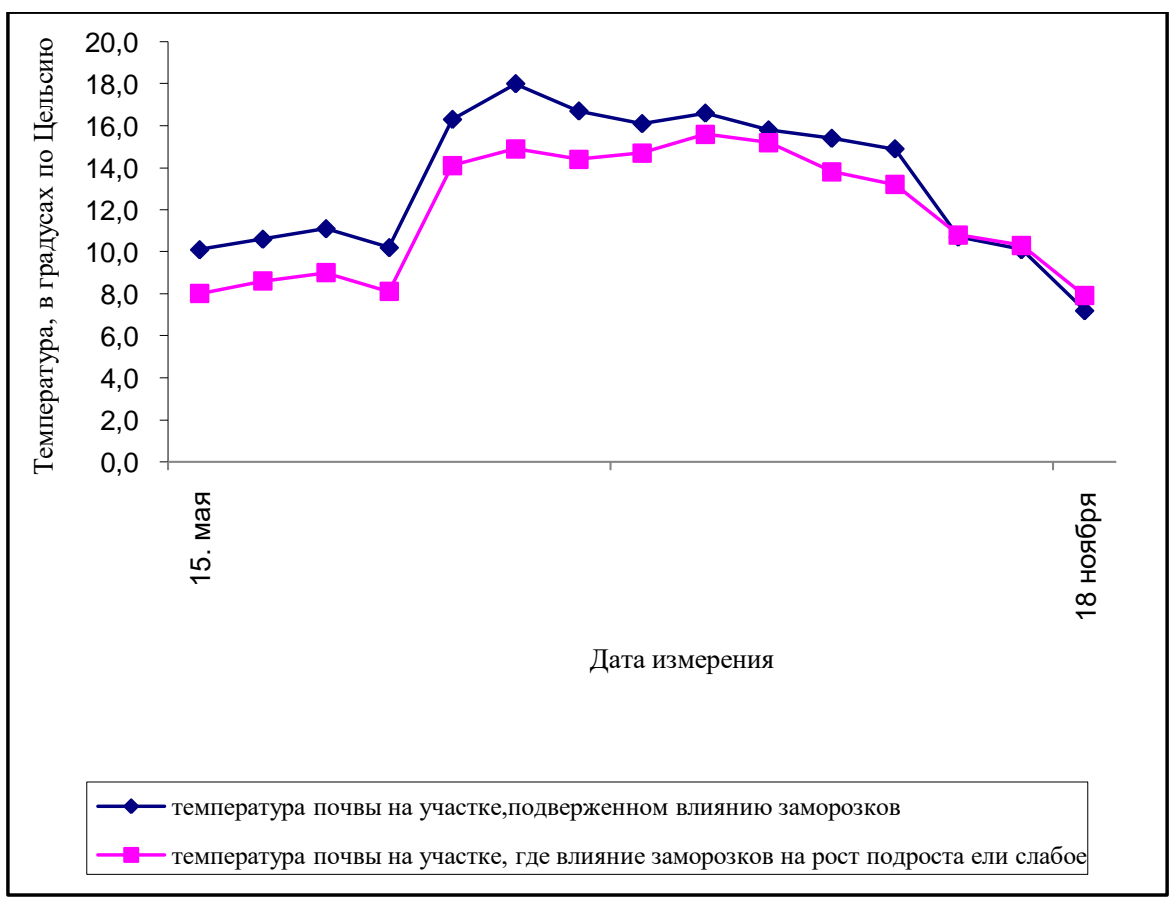

Рис. 1. Динамика изменения температурного режима почвы, в культурах ели (глубина измерения 15 см)

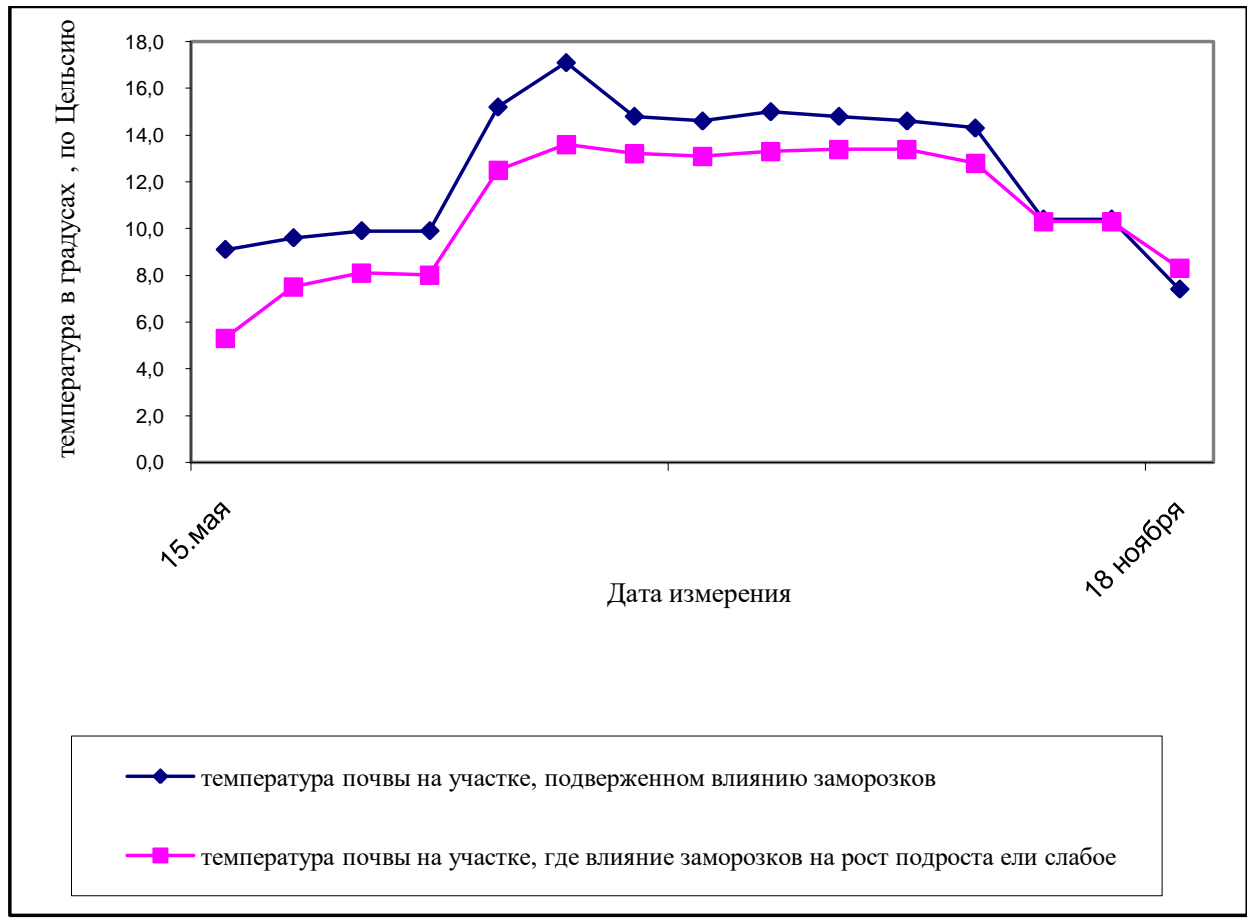

Рис. 2. Динамика изменения температурного режима почвы, в культурах ели (глубина измерения 30 см) 
Анализ полученных данных показал, что температура почвы полученных данных показал, что температура солнечного тепла. Так, если температура воздуха снижалась, то и температура почвы на 15 см глубине снижалась значительно, а на глубине $30 \mathrm{~cm}$ процесс снижения температуры сглаживался, понижение было незначительным.

Установлено, что в процессе вегетационного периода температурный режим почв на участках с различным влиянием заморозков на особи ели, значительно отличаются.

Так, на участке где особи ели почти не подвержены влиянию заморозков, прогревание почвы происходит значительно медленнее, оттаивание почвы происходит постепенно, а на участке где $100 \%$ особей ели повреждаются заморозками, оттаивание почвы и ее прогревание происходит более интенсивно. В процессе вегетационного периода до его окончания, температура почвы на участке, где $100 \%$ особей ели повреждаются заморозками, на 1-2 гр. выше, температуры почвы на участке не подверженном влиянию заморозков. В осенний период температурный режим почвы выравнивается, а затем при понижении температуры воздуха ниже температуры почвы, остывание почвы на участке со $100 \%$ процентным повреждением ели происходит более интенсивно, чем на участке где влияние заморозков минимальное.

Полученные данные свидетельствуют о влиянии температурного режима почвы на устойчивость особей ели к заморозкам. По всей видимости, это связано с влиянием температурного режима почв на гормональный баланс растения.

\section{Результаты и их обсуждения}

По данным таблицы 1 и 2 можно сделать вывод, что сумма минимальных ночных температур за наблюдаемый период связана со средней высотой: чем меньше сумма минимальных ночных температур, тем меньше средняя высота деревьев. Так на пробной площади 1 средняя высота составила 207.7 см., а сумма минимальных ночных температур на уровне кроны составила $90^{\circ} \mathrm{C}$; на пробе $2-\mathrm{H}$ ср. -213.6 см., а сумма минимальных ночных температур $98.7^{\circ} \mathrm{C}$; на пробе $3-\mathrm{H}$ ср. -149.5 см., а сумма минимальных ночных температур $70.9^{\circ} \mathrm{C}$.

После заморозка с 22 на 23 июня на пробной площади №1 пострадало 45\% всех особей, а на пробной площади №2 - 63\%. Средняя высота наиболее пострадавших особей на пробной площади №1, так и на пробной площади №2 была почти одинаковой, соответственно 183.7 см. и 188.7 см.. При этом значительно уступала средней высоте менее пострадавших особей в среднем на $20-40$ см..

При последующих заморозках количество пострадавших особей увеличивалось, но средняя высота деревьев, которые пострадали от заморозков в меньшей степени, была выше, чем у особей имеющих более высокую степень повреждения.

Три процента всех особей ели не пострадали от весенне-летних заморозков. Температурный режим почвы в корневой зоне оказывает влияние на устойчивость особей ели к заморозкам. По всей видимости, более быстрое прогревание верхних слоев почвы способствует более раннему началу процессов биосинтеза цитокининов в корнях растений, что приводит к более интенсивному повреждению растений отрицательными температурами.

\section{Заключение}

Установлено, что на степень повреждения текущего побега подроста Picea abies [L.] Karst. оказывает влияние содержание растворимых сахаров в текущих побегах. Температурный режим почвы в корневой зоне растений играет существенную роль в устойчивости особей ели к заморозкам. Более быстрое прогревание верхних слоев почвы способствует более раннему началу процессов биосинтеза цитокининов в корнях растений, что приводит к более сильному повреждению растений отрицательными температурами при вегетации. К снижению влияния данного фактора, приводит 
сохранение лиственных пород (березы) при рубках ухода, что способствует замедлению раннего прогревания верхних слоев почвы.

\section{Исследования проведены в ходе выполнение Государственного задания ФГБУН ФИЦКИА РАН АААА-А18-118012390305-7 $* * *$}

1. Бочарова М.А., Трунова Т.И., Шаповалов А.А., Баскаков Ю.А. Влияние картолина на морозостойкость озимой пшеницы // Физиология растений. 1983. Т.30. вып. 2. С 360-362.

2. Волкова Р. И., Дроздов С. Н., Сычева 3. Ф., Балагурова Н. И. О регуляторной функции ауксинов у активно вегетирующих растений при температурном воздействии // Физиология растений. 1992. т.28, в.3. С.615-620.

3. Трунова Т. И., Зверева Г. Н. Защитное действие сахаров при промораживании суспензии хлоропластов // Физиология растений. 1974. т.21. в. 5. С. 1000-1005.

4. Новицкая Ю. Е. Особенности физиолого-биохимических процессов в хвое и побегах ели в условиях Севера. Л.: Наука, 1971. 116 с.

5. Захарчук Н. В., Дорошенко Т. Н. Оценка морозно- и заморозкоустойчивости растений яблони // Управление экономическими системами: электронный научный журнал. 2013. № 49 (1). С. 22.

6. Дорошенко Т. Н., Максимцов Д. В., Бехтерев В. Н., Кожевникова А.М. Возможности диагностики устойчивости плодовых растений к весенним заморозкам. Физиолого-биохимический аспект // Труды Кубанского аграрного университета. 2012. №38. С. 65-67.

7. Hanners Mats. Damages to Norway spruse (Picea abies (L) Karst) seedling caused bu Latk spring frost // Rept/Skoog Forsk. 1994. № 5. C.55-57.

8. Ирошников А. И. Методика изучения внутривидовой изменчивости древесных пород. М. $1973.31 \mathrm{c}$.

9. Плешков Б. Н. Практикум по биохимии растений. 1985. 255c. 